\title{
Effects of Machining Parameters on Tool Steel D2 in Wire cut EDM
}

\author{
Pankaj R. Patil ${ }^{1}$, P.M.Solanki ${ }^{2}$, Dr.S.P.Shekhawat ${ }^{3}$, \\ ${ }^{I}$ P.G Scholar, Department of Mechanical Engineering, SSBTS COET, Jalgaon. \\ ${ }^{2}$ Assistant Professor, Department of Mechanical Engineering, SSBTs COET, Jalgaon. \\ ${ }^{3} H O D$, Department of Mechanical Engineering, SSBTs COET, Jalgaon
}

\begin{abstract}
Non-conventional machining process like electro discharge machining (EDM) and wire electrical discharge machining (WEDM) plays important role in precision manufacturing process. This micro-machining process may help overcome the limitations and restriction faced during conventional mechanical machining process.The selection of machining parameters in any machining process significantly affects production rate, product quality and production cost of a finished one component. Wire EDM process involves a large number of variables that affect its performance. In this paper, an attempt is made to study the effect of various process parameters such as pulse on time, pulse off time and current for high carbon high chromium cold work tool steel $\left(D_{2}\right)$. The experiment has been completed with the help of Design of experiment by Taguchi method is applied to create an orthogonal array of input variables using the ANOVA. The regression analysis is used to optimize the process parameter of Surface roughness. The experimental analysis showed that the combination of pulse on time, pulse off time and current is optimum to achieve minimization of surface roughness (Ra).
\end{abstract}

Keywords: Taguchi DOE, ANOVA, Regression Analysis.

\section{Introduction}

WEDM is considered as a unique adoption of the conventional EDM process, which uses an electrode to initialize the sparking process. However, WEDM utilizes a continuously travelling wire electrode made of thin copper, brass, tungsten or molybdenum of diameter $0.05-0.30 \mathrm{~mm}$, which is capable of achieving very small corner radii. The wire is kept in tension using a mechanical tensioning device reducing the tendency of producing inaccurate parts. During the WEDM process, the material is eroded ahead of the wire and there is no direct contact between the work piece and the wire, eliminating the mechanical stresses during machining. Machining removes certain parts of the work pieces to change them to final parts.. This paper investigates the interactions between common process parameters of WEDM and final quality of the generated surface, through analysis of variance (ANOVA) and regression models based on experimental results. In particular, the paper is focused on the effects of pulse on time, pulse off time, and current on the surface finish during the WEDM of a WPS D2 (War Purpose Steel)D2 material. Results showed that, it is possible to state that all the considered variables affect directly or indirectly by means of interactions, the surface roughness indices. It is also worth to underline that the combined optimization of Ra, Rt, and $\mathrm{R}$ appears to be a difficult task, due to the counteracting effects of input parameters. V.Chengal Reddy [2015] in their work an attempt is made to study the effect of Various process parameters such as pulse on time, pulse off time, wire tension, current, upper flush and lower flush for Aluminium HE30. The experimentation has been completed with the help of Taguchi grey relational analysis. Taguchi grey relational analysis is used to optimize the process parameters on multiple performance characteristics such as Material removal rate, surface finish. The experimental result analysis showed that the combination of pulse on time, pulse off time, wire tension, lower flush, wire tension and upper flush is essential to achieve maximization of material removal rate and minimization of surface roughness and kerf width.

Kashid D.V [2014] presented their work, the parametric optimization method using Taguchi method is proposed for WEDM of steel grade EN 9 component. Three process parameters are selected for this investigation; Pulse on-time, Pulse off-time and wire feed. The experimentation is conducted by using Taguchi's L9 orthogonal array. Signal to Noise ratios of the Material removal rate for all experiments are calculated. From above results, we were concluding that material removal rate was highly influenced by pulse-on time and pulseoff time. The higher discharge energy, the more powerful explosion and the deeper crater created on the machined area. Pulse on-time (TON) with a contribution of $51.7103 \%$ has greatest effect on the machining output characteristics. Parameter pulse-off time (TOFF) is the next most significant influence $42.153 \%$ on the material removal rate. It reveals that wire feed rate has less effect on the material removal rate as compare to pulse on-time and pulse-off time. Hence if requirement of material removal rate is high, then pulse on-time and pulse-off time must high. S V Subrahmanyam [2013] in their work an attempt is made to study the optimization of Wire Electrical Discharge Machining process parameters for the machining of H13 HOT DIE STEEL, with multiple responses Material Removal Rate (MRR), surface roughness (Ra) based on the Grey-Taguchi Method. 
taguchi'sL27(21x38) Orthogonal Array was used to conduct experiments, which correspond to randomly chosen different combinations of process parameter setting, with eight process parameters: TON, TOFF, IP, SV WF, WT,SF, WP each to be varied in three different levels. Data related to the each response viz. material removal rate (MRR), surface roughness (Ra) have been measured for each experimental run; With Grey Relational Analysis Optimal levels of process parameters were identified. The relatively significant parameters were determined by Analysis of Variance. The variation of output responses with process parameters were mathematically modeled by using non-linear regression analysis. The models were checked for their adequacy.Results showed that, while applying the Grey-Taguchi method using L36 orthogonal array. it is observed that the Material Removal Rate increased, Surface Roughness reduced, which are positive indicators of efficiency in the machining process. Thus, it can be concluded that the Grey-Taguchi Method, is most ideal and suitable for the parametric optimization of the Wire-Cut EDM process, when using the multiple performance characteristics such as MRR (Material Removal Rate), Surface Roughness for machining the H13 or for the matter for any other material. Mathematical relations between the machining parameters and performance characteristics established.

Jangra Kamal et al [2012] are study the inter-relationship among various input parameters such as Pulse on Time, Pulse off Time, Peak current, Wire speed and Wire tension with output measures namely Cutting Speed, Surface Roughness and Dimensional lag in wire electrical discharge machining of D3 tool steel as a work piece material and using Taguchi and Grey Relational Analysis techniques. It has proved using GRA, optimal setting of process parameters for multiple performance characteristics was set with A5B2C1D1E2 corresponding predict values were confirmed experimentally that the cutting speed was observed $3.80 \mathrm{~mm} / \mathrm{min}$ and surface finish was poor and it can be improved by assigning high weightage in grey relational grade.

\section{D2 Tool Steel - High-Carbon, High-Chromium, Cold-Work Steel \\ II. Methodology}

The principal steels of wide application for long-run dies are steels in this group. Grade D2 containing $1.50 \%$ carbon is of moderate toughness and intermediate wear resistance. Selection between the grades is based on the length of run desired, machining and grinding problems. From D2 steel all group D steels have $1 \%$ Mo and are air hardened. Type D2 steel is oil-quenched; though small sections can be gas quenched after austenitization using vacuum. As a result, tools made with type $\mathrm{D}_{2}$ steel tend to be brittle during hardening. Type D2 steel is the most commonly used steel among the group D steels. The D2 steels contain 1.5 to $2.35 \%$ of carbon and $12 \%$ of chromium.

\section{Chemical Composition}

The following table shows the chemical composition of D2 tool steels.

\begin{tabular}{|c|c|}
\hline Element & Content (\%) \\
\hline $\mathrm{C}$ & $1.40-1.60$ \\
\hline $\mathrm{Mn}$ & 0.60 \\
\hline $\mathrm{Si}$ & 0.60 \\
\hline $\mathrm{Co}$ & 1.00 \\
\hline $\mathrm{Cr}$ & $11.00-13.00$ \\
\hline $\mathrm{Mo}$ & $0.70-1.20$ \\
\hline $\mathrm{V}$ & 1.10 \\
\hline $\mathrm{P}$ & 0.03 \\
\hline $\mathrm{Ni}$ & 0.30 \\
\hline $\mathrm{Cu}$ & 0.25 \\
\hline
\end{tabular}

Table 1.Chemical Properties

Physical Properties

The physical properties of D2 tool steels are outlined in the following table.

\begin{tabular}{|c|c|c|}
\hline Properties & Metric & Imperial \\
\hline Density & $7.7 \times 1000 \mathrm{~kg} / \mathrm{m}^{3}$ & $0.278 \mathrm{lb} / \mathrm{in}^{3}$ \\
\hline Melting Point & $1421^{\circ} \mathrm{C}$ & $2590^{\circ} \mathrm{F}$ \\
\hline
\end{tabular}

Table 2.physical Properties

Mechanical Properties

The mechanical properties of D2 steels are tabulated below:

\begin{tabular}{|c|c|c|}
\hline Mechanical Properties & Metric & Imperial \\
\hline $\begin{array}{c}\text { Hardness, Knoop (converted from } \\
\text { Rockwell C hardness) }\end{array}$ & 769 & 769 \\
\hline Hardness, Rockwell C & 62 & 62 \\
\hline Hardness, Vickers & 748 & 748 \\
\hline Izod impact unnotched & $77.0 \mathrm{~J}$ & $56.8 \mathrm{ft}-\mathrm{lb}$ \\
\hline
\end{tabular}




\begin{tabular}{|c|c|c|}
\hline Poisson's ratio & $0.27-0.30$ & $0.27-0.30$ \\
\hline Elastic modulus & $190-210 \mathrm{GPa}$ & $27557-30457 \mathrm{ksi}$ \\
\hline
\end{tabular}

Table 3.Mechanical Properties

Thermal Properties

The following table shows the thermal properties of D2 steels.

\begin{tabular}{|l|c|c|}
\hline Properties & \multicolumn{2}{|c|}{ Conditions } \\
\cline { 2 - 3 } & $\mathbf{T}\left({ }^{\circ} \mathbf{C}\right)$ & Treatment \\
\hline Thermal expansion & $10.4 \times 10^{-6} /{ }^{\circ} \mathrm{C}$ & $20-100$ \\
\hline
\end{tabular}

Table 4.Thermal Properties

\section{Experimental Analysis Method}

Methods adopted for analysis of trials are Taguchi Method and Regression Analysis Design of Experiments (DOE) is a powerful technique used for exploring new processes, gaining increased knowledge of the existing processes and optimizing these processes for achieving world class performance. Design of Experiments refers to the process of planning, designing and analyzing the experiment so that valid and objective conclusions can be drawn effectively and efficiently. In order to draw statistically sound conclusions from the experiment, it is necessary to integrate simple and powerful statistical methods into the experimental design methodology. The success of any industrially designed experiment depends on sound planning, appropriate choice of design, and statistical analysis of data and teamwork skills. The Taguchi approach is a DOE method that has been widely used in industrial robust design procedures. Several studies have been made on design of cutting processes using the Taguchi approach. Though this approach can identify the main effects of separate design factors, it is limited in that interactions among those factors cannot be considered effectively. The DOE procedure consists of the following four steps

a) Planning: definition of the problem and the objective, and development of an experimental plan.

b) Screening: reduction of the number of variables by identifying the key variables that affect product quality.

c) Optimization: determination of the optimal values for various experimental factors.

d) Verification: performing a follow-up experiment at the predicted best processing conditions to confirm the optimization, results.

\section{Deign Of Experiments by Taguchi Method}

Taguchi techniques were developed by Taguchi and Konishi, these techniques have been utilized widely in engineering analysis to optimize the performance characteristics within the combination of design parameters. Taguchi technique is also power tool for the design of high quality systems. It introduces an integrated approach that is simple and efficient to find the best range of designs for quality, performance, and computational cost.

In product or process design of Taguchi method, there are three steps:

1. System design: selection of a system for a given objective function

2. Parameter design: selection of the optimum levels of parameters

3. Tolerance design: determination of tolerance around each parameter level.

In this study, parameter design is coupled to achieve the optimum levels of process parameters leading to minimum shrinkage during the manufacturing of plastic parts. In this study, Taguchi parameter design was used for identifying the significant processing parameters and optimizing the minimum shrinkage. Two important tools used in parameter design are orthogonal arrays and signal-to-noise $(\mathrm{S} / \mathrm{N})$ ratios. Figure 4.1 demonstrates the steps of Taguchi parameter design.

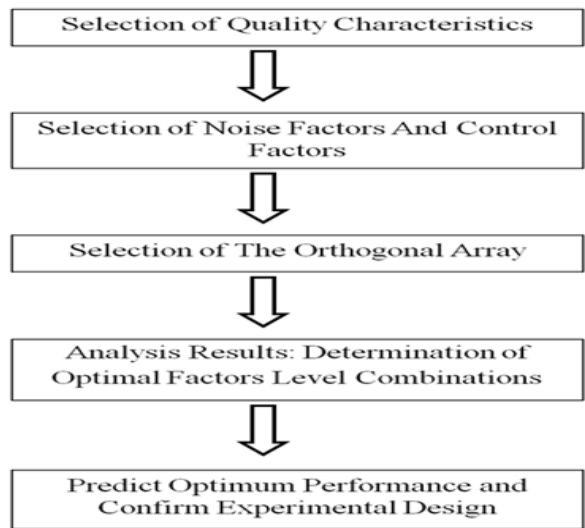

Fig 1. Steps of Taguchi Parameter Design. 


\section{Selection of the quality characteristic}

There are three types of quality characteristics in the Taguchi methodology such as the-smaller-the-better, thelarger the -better, and the-nominal-the-best. Signal to Noise analysis is designed to measure quality characteristic. It is given by

$\mathrm{S} / \mathrm{N}=-10 \log _{10}$ (MSD)

Where MSD= Mean Squared Division

For the smaller the better characteristic, $M S D=\left(Y_{1}^{2}+Y_{2}^{2}+Y_{3}^{2}+\ldots \ldots \ldots . ..\right) / n$

Larger the better characteristic,

$M S D=\left(1 / Y_{1}^{2}+1 / Y_{2}^{2}+1 / Y_{3}^{2}+\ldots \ldots \ldots . ..\right) / n$

Nominal the best characteristic,

$\left.\mathrm{MSD}=\left[\left(\mathrm{Y}_{1}-\mathrm{m}\right)^{2}+\left(\mathrm{Y}_{1}-\mathrm{m}\right)^{2}+\left(\mathrm{Y}_{1}-\mathrm{m}\right)^{2}+\cdots \cdots \cdot\right)\right] / \mathrm{n}$

Where $\mathrm{Y}_{1}, \mathrm{Y}_{2}, \mathrm{Y}_{3}$ are the responses and $\mathrm{n}$ is the number of tests in a trial and $\mathrm{m}$ is the target value of the result.

\section{Selection of Parameters and Their Levels}

Roughness is often a good predictor of the performance of a mechanical component, since irregularities in the surface may form nucleation sites for cracks or corrosion. Roughness is measure of texture of a surface. It is qualified by the vertical deviations of a real surface from its ideal form. If these deviations are large, the surface is rough; if small, the surface is smooth. Roughness is typically considered to be the high frequency, short wavelength component of a measured surface. The parameter mostly used for general surface roughness is $\mathrm{Ra}$. It measures average roughness by comparing all the peaks and valleys to the mean line, and then averaging them all over the entire cut-off length. The surface roughness can be measured using a surface roughness tester machine, which is shown in Fig.

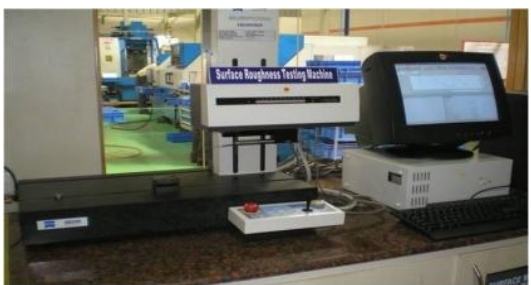

Fig 2. Equipment for Surface Roughness Measurement

The top 3 from the list of 9 qualified factors were selected for the study. To keep the size of the experiment small and study as many factors as possible, all factors were studied at two extreme ranges of values (2 levels). These factors and their levels are shown next. Surface roughness is govern by various control factors such as

1) Current

2) Pulse on Time

3) Pulse off Time

4) Pulse width

5) Pulse interval

6) Speed

7) Applied Voltage

8) Wire speed

9) Wire Tension

The top 3 from the list of 9 qualified factors were selected for the study. To keep the size of the experiment small and study as many factors as possible, all factors were studied at 3 levels. These factors and their levels are shown next.

\begin{tabular}{|c|c|c|c|c|}
\hline Notation & Factor Description & Level 1 & Level 2 & Level 3 \\
\hline A & Current (Amp.) & 5 & 7 & 9 \\
\hline B & Pulse On Time $(\mu \mathrm{s})$ & 16 & 32 & 48 \\
\hline C & Pulse Off Time $(\mu \mathrm{s})$ & 6 & 8 & 10 \\
\hline
\end{tabular}

Table 5. Control Factors and Levels for WPS D2 material

Selection of Orthogonal Array

Because there are only 3 3-level factors and no interaction is selected an L-9 array is used to design the experiment as shown below 


\begin{tabular}{|c|c|c|c|c|c|}
\hline $\begin{array}{c}\text { Exp. } \\
\text { No. }\end{array}$ & $\begin{array}{c}\mathbf{A} \\
\text { Current } \\
(\text { Amp) }\end{array}$ & $\begin{array}{c}\text { B } \\
\text { Pulse on } \\
\text { Time }(\boldsymbol{\mu s})\end{array}$ & $\begin{array}{c}\text { C } \\
\text { Pulse off } \\
\text { Time }(\boldsymbol{\mu s})\end{array}$ & Average & S/N Ratio \\
\hline 1 & 5 & 16 & 6 & 3.30 & -10.3703 \\
\hline 2 & 5 & 32 & 8 & 3.58 & -11.0777 \\
\hline 3 & 5 & 48 & 10 & 3.90 & -11.8213 \\
\hline 4 & 7 & 16 & 8 & 5.00 & -13.9794 \\
\hline 5 & 7 & 32 & 10 & 4.90 & -13.8039 \\
\hline 6 & 7 & 48 & 6 & 5.15 & -14.2361 \\
\hline 7 & 9 & 16 & 10 & 6.60 & -16.3909 \\
\hline 8 & 9 & 32 & 6 & 6.30 & -15.9868 \\
\hline 9 & 9 & 48 & 8 & 6.80 & -16.6502 \\
\hline
\end{tabular}

Table 6.Layout for Experimental Design according to $\mathrm{L}_{9}$ Array for WPS D2 material

\begin{tabular}{|c|c|c|c|c|}
\hline Notation & Factor Description & Level 1 & Level 2 & Level 3 \\
\hline A & Current $($ Amp.) & 5 & 7 & 9 \\
\hline B & Pulse On Time $(\mu \mathrm{s})$ & 16 & 32 & 48 \\
\hline C & Pulse Off Time $(\mu \mathrm{s})$ & 6 & 8 & 10 \\
\hline
\end{tabular}

Table 7. Response table for Signal to Noise Ratio of WPS D2 material

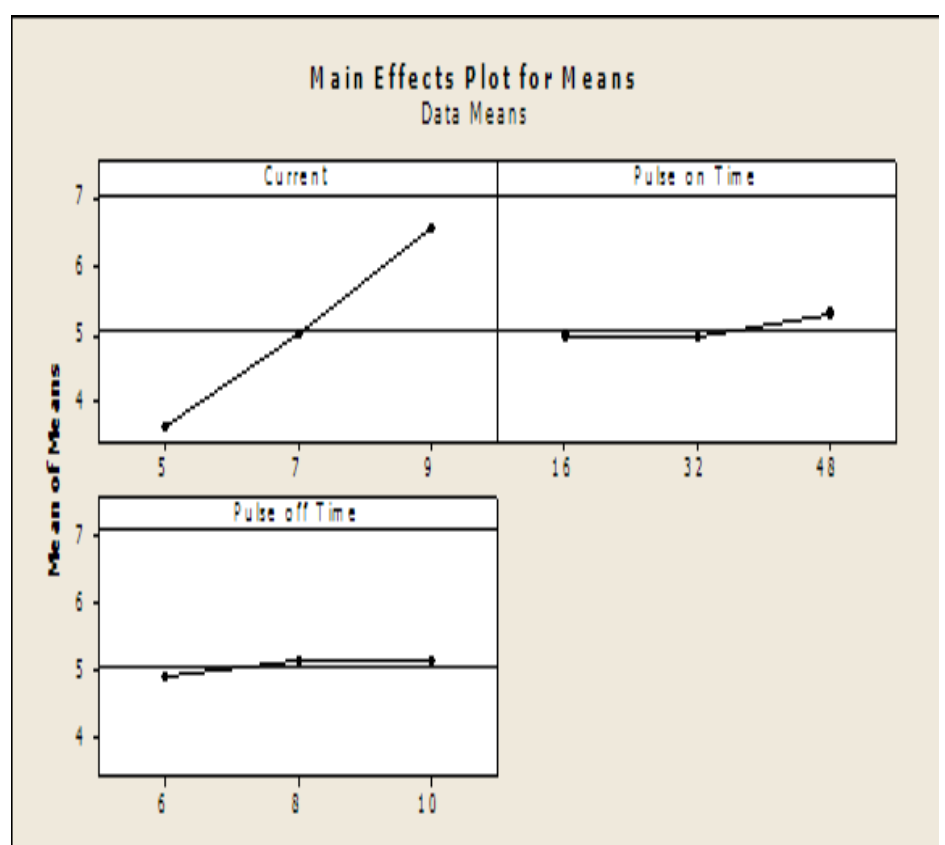

Graph 1. Main Effect Plot for Average RA for WPS D2 Material

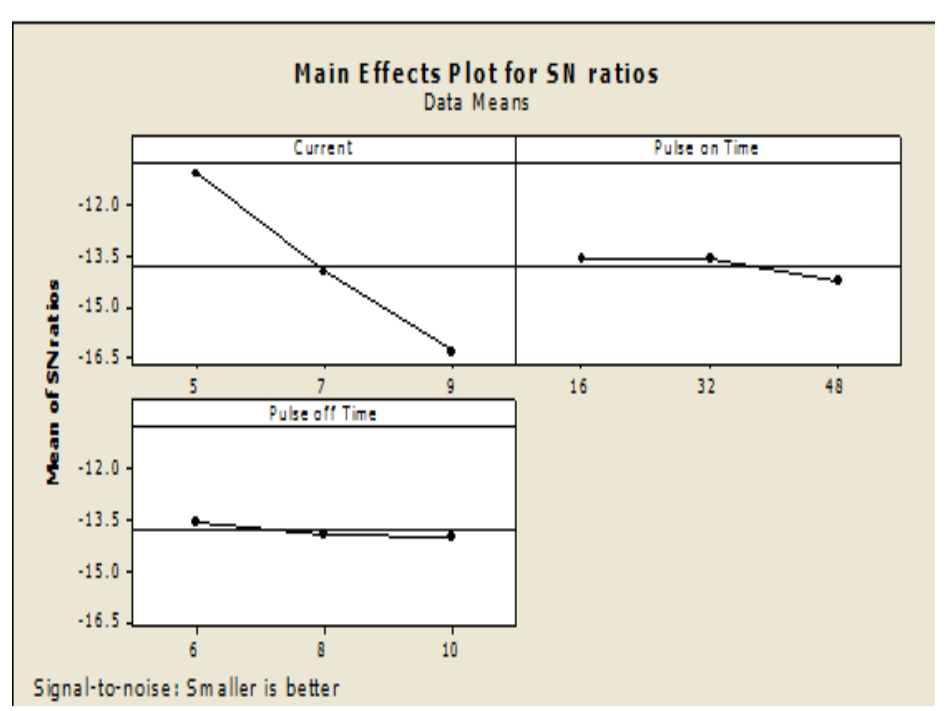

Graph 2. Main Effect Plot for S/N Ratio for WPS D2 material 


\begin{tabular}{|l|l|l|l|}
\hline Level & Current & Pulse on Time & Pulse off Time \\
\hline 1 & -11.09 & -13.58 & -13.53 \\
\hline 2 & -14.01 & -13.62 & -13.90 \\
\hline 3 & -16.34 & -14.24 & -14.01 \\
\hline Delta & 5.25 & 0.66 & 0.47 \\
\hline Rank & 1 & 2 & 3 \\
\hline
\end{tabular}

Table 8. Response table for Signal to Noise Ratio of WPS D2 material

\begin{tabular}{|l|l|l|l|l|l|l|}
\hline Source & DOF & Seq.SS & Adj.SS & Adj.MS & F & P \\
\hline Current & 2 & 41.5577 & 41.5577 & 20.7788 & 218.80 & 0.005 \\
\hline $\begin{array}{l}\text { Pulse on } \\
\text { Time }\end{array}$ & 2 & 0.8076 & 0.8076 & 0.4038 & 4.25 & 0.190 \\
\hline $\begin{array}{l}\text { Pulse off } \\
\text { time }\end{array}$ & 2 & 0.3734 & 0.3734 & 0.1867 & 1.97 & 0.337 \\
\hline $\begin{array}{l}\text { Residual } \\
\text { Error }\end{array}$ & 2 & 0.1899 & 0.1899 & 0.0950 & & \\
\hline Total & 8 & 42.9286 & & & & \\
\hline
\end{tabular}

$S=0.308167$

Table 9.Analysis of Variance for Signal to Noise Ratio of WPS D2 material $\mathrm{R}-\mathrm{sq}=99.56 \%$

$\mathrm{R}-\mathrm{Sq}($ Adj. $)=98.23 \%$

After machining of WPS D2 material on EDM, it can be noted that Current has the largest effect on the surface roughness. The pulse off has the smallest effect on the surface roughness. To attain better surface finish, surface roughness has to be minimized. From above main effect plot, it can observed that for the three levels of peak currents the surface roughness is declining linearly and at current level 9 amp the Surface roughness value is the lowest (-16.34). Similarly Surface roughness also diminishes with increased levels of both, pulse on time and pulse off time. At pulse on time $(48 \mu \mathrm{s})$ the SR value observed was the least i.e. -14.24 also for Pulse off time $(10 \mu \mathrm{s})$ the smallest SR value (14.01) was monitored. Thus the optimum condition for surface roughness observed were, A3, B3, and C3 i.e. Current ( 9 amp.), Pulse-on (48 $\mu$ s) and Pulse off time (10 $\mu$ s). Interaction plot fig. 4.1 and fig. 4.2 which is the combination of all three parameters interacting with each other at different levels gives the idea that current, pulse on time and pulse off time had their considerable effects on WPS D2 material surface roughness while machining with EDM.

\section{Prediction Model}

Regression analysis is used to find the mathematical model to predict surface roughness for the present work. In the model, Surface Roughness is assumed as function of Current, Pulse on time and Pulse off time. The relationship between surface roughness and other input variables is modelled as fallows.

The regression equation is

SNRA $=-3.02-1.31 * \mathrm{~A}-0.0205 * \mathrm{~B}-0.119 * \mathrm{C}$

$\mathrm{SNRA}=\mathrm{S} / \mathrm{N}$ Ratio of Avg. Surface Roughness

$\mathrm{A}=$ Current (Amp.)

$\mathrm{B}=$ Pulse on Time $(\mu \mathrm{s})$

$\mathrm{C}=$ Pulse off Time $(\mu \mathrm{s})$

The optimal level obtained by $\mathrm{S} / \mathrm{N}$ ratio analysis is $\mathrm{A}_{3}, \mathrm{~B}_{3}$, and $\mathrm{C} 3$

\begin{tabular}{|l|l|l|}
\hline Sr.No. & Factors & Level Description \\
\hline 1 & Current (Amp.) & 9 \\
\hline 2 & Pulse on Time $(\mu \mathrm{s})$ & 48 \\
\hline 3 & Pulse on Time $(\mu \mathrm{s})$ & 10 \\
\hline
\end{tabular}

Substituting these values in above regression equation

$($ SNRA)opt $=-3.02-1.31 * \mathrm{~A}-0.0205 * \mathrm{~B}-0.119 * \mathrm{C}$

$($ SNRA)opt $=-3.02-1.31 * 9-0.0205 * 48-0.119 * 10($ SNRA)opt $=-16.984$ (Predicted by Regression

Equation)

$\mathrm{S} / \mathrm{N}$ Ratio of average Ra values obtained by validation experiment SNRA (actual) $=-16.5$

Error $=($ SNRA $)$ actual $-($ SNRA $)$ predicted

Error $=-16.5-(-16.984)=0.484$

$\%$ Error $=0.0293$ 


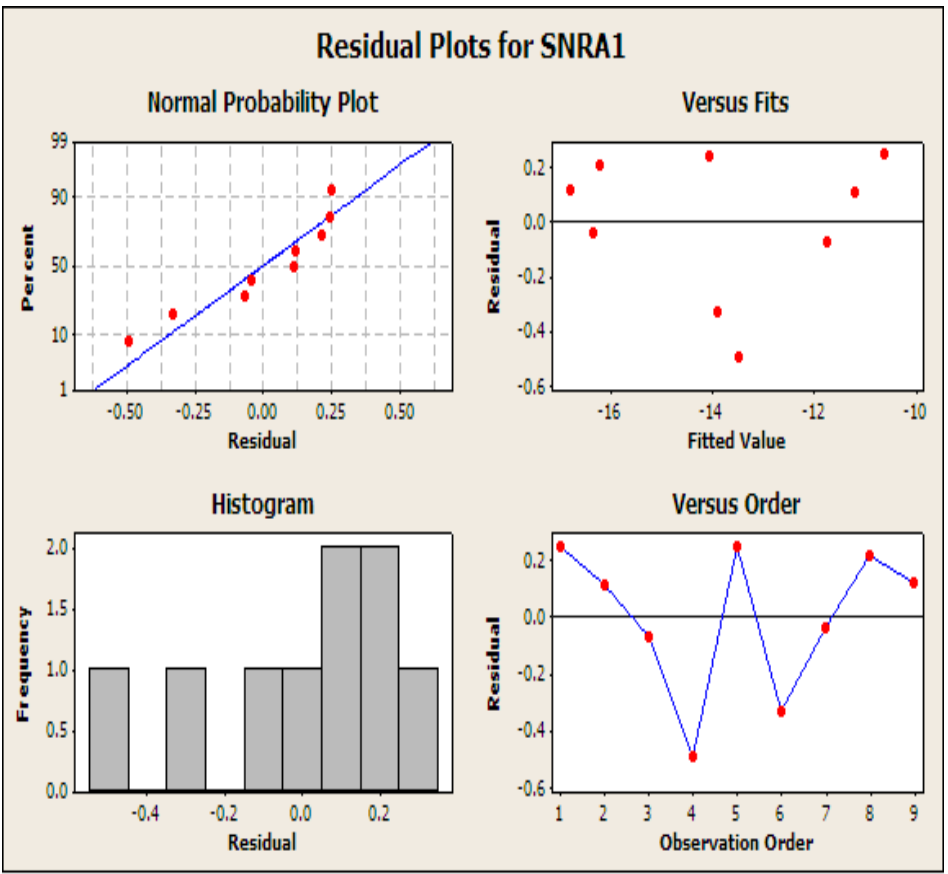

Graph3: Prediction and Residual Plots for SNRA for WPS-D2 Material

\subsection{Conclusion}

The Taguchi method was applied to find an optimal setting of the Wire cut EDM process. The result from the Taguchi method chooses an optimal solution from combinations of factors if it gives minimized normalized combined S/N ratio of targeted outputs. The L-9 OA was used to accommodate three control factors and each with 3 levels for experimental plan selected process parameters are Current, Pulse on Time, Pulse off Time for both the materials i.e. WPS D2. The results are summarized as follows:

i.Among the three process parameters for cutting of WPS D2 material current has significant effect on Quality Characteristic.

ii.For WPS D2 material maximization of current gives maximum surface finish of component.

iii.The Optimal level of process parameter for WPS D2 material were found to be A3, B3, and C3 i.e. Current (9 amp.), Pulse-on (48 $\mu$ s) and Pulse off time (10 $\mu$ s).

iv.The predictions made by Taguchi parameter design technique are in good agreement with confirmation results.

v.The result of present investigation are valid within specified range of process parameters

vi The developed model gives the predicted values against the actual SNRA values. The residuals tend to be close to diagonal line indicating that the developed model is adequate, confirmation tests are conducted by using new conditions at optimal levels as obtained by using MINITAB Software.

vii.Also the prediction made by Regression Analysis is in good agreement with confirmation results.

\section{Reference}

[1]. Yan ,Mu-Tian \& Chiang,Tsung-Liang, Design and experimental study of a power supply for micro-wire EDM, Int J Adv Manuf Technol (2009) 40.

[2]. Norliana Mohd Abbas, Darius G. Solomon, Md. Fuad Bahari, A review on current research trends in electrical discharge machining (EDM), International Journal of Machine Tools \& Manufacture 47 (2007) .

[3]. K.H. Ho, S.T. Newman, State of the art electrical discharge machining (EDM),International Journal of Machine Tools \& Manufacture 43 (2003).

[4]. Dhar, s., Purohit, r., Saini, n., Sharma, a. and Kumar, G.H., 2007. Mathematical modeling of electric discharge machining of cast Al-4Cu-6Si alloy-10 wt.\% sicp composites. Journal of Materials Processing Technology, 193(1-3), 24-29.

[5]. Karthikeyan R, Lakshmi Narayanan, P.R. and Naagarazan, R.S., 1999. Mathematical modeling for electric discharge machining of aluminium-silicon carbide particulate composites. Journal of Materials Processing Technology, 87(1-3), 59-63.

[6]. S V Subrahmanyam, M. M. M. Sarcar, Evaluation of Optimal Parameters for machining with Wire cut EDM Using Grey-Taguchi Method, International Journal of Scientific and Research Publications, Volume 3, Issue 3, March 2013 ISSN 2250-3153.

[7]. Kashid D.V., S.G. Bhatwadekar, S.B. Sangale, P.R. Kubade, Investigations of Effect of Process Parameters on Material Removal Rate in Wirecut Electrical Discharge Machining of Steel Grade EN 9, Journal of IJEERT, 2014, Volume 2, Issue 1, April 2014, PP 31-35.

[8]. V.Chengal Reddy, N.Deepthi, N.Jayakrishna, Multiple Response Optimization of Wire EDM on Aluminium HE30 by using Grey Relational Analysis, Journal of ELSEVIER, 2015, Proceedings 2, $2548-2554$.

[9]. El-Taweel, T.A., 2009. Multi-response optimization of EDM with Al-Cu-Si-tic P/M composite electrode. International Journal of Advanced Manufacturing Technology, 44(1-2), 100-113. 
[10]. Mohan, B., Rajadurai, A. and Satyanarayana, K.G., 2002. Effect of sic and rotation of electrode on electric discharge machining of Al-sic composite. Journal of Materials Processing Technology, 124(3), 297-304.

[11]. Lin, y.-., Cheng, C.-., Su, B.-. and Hwang, L.-., 2006. Machining characteristics and optimization of machining parameters of SKH 57 high-speed steel using electrical-discharge machining based on Taguchi method. Materials and Manufacturing Processes, 21(8), 922-929.

[12]. J. Simao, H.G. Lee, D.K. Aspinwall, R.C. Dewes, and E.M. Aspinwall 2003.Workpiece surface modification using electrical discharge machining, , 43 (2003) 121-128

[13]. Singh, P.N., Raghukandan, K., Rathinasabapathi, M. And Pai, B.C., 2004. Electric discharge machining of Al-10\%sicp as-cast metal matrix composites. Journal of Materials Processing Technology, 155-156(1-3), 1653-1657. 